Revue d'histoire de l'Amérique française

REYUE D.HISTOIRE DE L'AMÉRIQUE FRANÇAISE

FILION, Mario, Jean-Charles FORTIN, Robert LAGASSÉ, Richard LAGRANGE, Lorne HUSTON, Pierre LAMBERT et Roland VIAU, Histoire du Richelieu-Yamaska-Rive sud (Sainte-Foy, Institut québécois de recherche sur la culture, coll. " Les régions du Québec », 2001), 557 p.

\title{
Christian Morissonneau
}

Volume 56, numéro 3, hiver 2003

URI : https://id.erudit.org/iderudit/007623ar

DOI : https://doi.org/10.7202/007623ar

Aller au sommaire du numéro

\section{Éditeur(s)}

Institut d'histoire de l'Amérique française

ISSN

0035-2357 (imprimé)

1492-1383 (numérique)

Découvrir la revue

Citer ce compte rendu

Morissonneau, C. (2003). Compte rendu de [FILION, Mario, Jean-Charles FORTIN, Robert LAGASSÉ, Richard LAGRANGE, Lorne HUSTON, Pierre LAMBERT et Roland VIAU, Histoire du Richelieu-Yamaska-Rive sud (Sainte-Foy, Institut québécois de recherche sur la culture, coll. « Les régions du Québec », 2001), 557 p.] Revue d'histoire de l'Amérique française, 56(3), 400-402.

https://doi.org/10.7202/007623ar services d'Érudit (y compris la reproduction) est assujettie à sa politique d'utilisation que vous pouvez consulter en ligne.

https://apropos.erudit.org/fr/usagers/politique-dutilisation/ 
FILION, Mario, Jean-Charles FORTIN, Robert LAGASSÉ, Richard LAGRANGE, Lorne HUSTON, Pierre LAMBERT et Roland VIAU, Histoire du Richelieu-Yamaska-Rive sud (Sainte-Foy, Institut québécois de recherche sur la culture, coll. «Les régions du Québec», 2001), 557 p.

Ce livre est le treizième de la collection «Les régions du Québec» publié par l'Institut québécois de la recherche sur la culture, maintenant Institut national de la recherche scientifique. Il est le troisième volume consacré à la Montérégie, vaste région administrative créée en 1985, et allant de Sorel à Rigaud en passant par Granby et le lac Champlain. On peut se poser la question d'une éventuelle appartenance ou conscience régionale.

Les sept auteurs qui se sont attaqués à l'histoire de ce grand morceau du territoire québécois dont le toponyme même était nouveau, ont fait le bon choix de le diviser selon "trois régions historiques nettement identifiables» (introduction, p. 17). En même temps, le consensus s'étant fait sur le découpage devenu presque familier des municipalités régionales de comté, il fallait garder «le respect de leurs frontières».

Je m'interroge sur cette région historique qui serait «nettement identifiable». L'identification ne doit pas être si facile puisqu'il faut trois toponymes pour ce faire. Quand bien même il existe géographiquement trois vallées auxquelles s'identifier : celles des rivières Richelieu et Yamaska et la Rive Sud du Saint-Laurent, je ne vois pas émerger de région historique les incluant toutes.

Brièvement, en raison de sa situation stratégique dans le prolongement de l'axe fluvial Montréal-New York, alors qu'il s'agit «d’une région née de la guerre» (p. 69), comme le dit si clairement le troisième chapitre du livre, et que cette rivière est comme la colonne vertébrale du territoire désigné, cette région aurait pu, au moins pour fins de rédaction, s'appeler tout simplement et justement Richelieu ou Vallée du Richelieu. Parce que, à l'évidence, après le fleuve, le Richelieu est le cours d'eau le plus chargé d'histoire.

Ces quelques lignes pour montrer que si la Montérégie est une courtepointe ou plutôt des papiers collés, la division en trois fragments géolivresques ne parvient pas plus à donner à ce volume 13, lui-même présenté en trinité, un sentiment d'identité régionale qui pourrait rassembler les habitants du Richelieu-Yamaska-Rive Sud.

Treize chapitres découpent cette synthèse régionale. Ils sont thématiques et la chronologie n'est annoncée qu'à l'intérieur des thèmes. Il n'est pas certain que le lecteur y gagne.

Pierre Lambert, en présentant le milieu naturel, montre bien que le «Jardin du Québec» a des explications géographiques. Il termine sur un énoncé inquiétant — «Un milieu domestiqué mais dégradé» — et sur le 
triste constat : "Aujourd'hui, la Montérégie est considérée comme la région la plus agressée sur le plan environnemental, avec notamment, une production de $40 \%$ des déchets dangereux du Québec.» (p. 40)

«L'Histoire avant l'Histoire» qu'aborde Roland Viau fait remonter à 6000 ans l'occupation amérindienne. Vers l'an mil de notre ère apparaît la «révolution culturale» dans cette région de la Laurentie iroquoïenne, avec des expériences agricoles et horticoles qui bouleverseront le genre de vie de ces Amérindiens chasseurs, puis chasseurs-pêcheurs, déjà installés dans la vallée du Saint-Laurent. Donc oui à l'évolution in situ des Iroquoïens, dont les ancêtres auraient été «des nouveaux arrivants [qui] affirmeront leur ethnicité et leur identité régionale» (p. 48). Le chapitre se clôt avec la description des Iroquoïens de la région qui font partie de deux aires culturelles : Hochelaga et Maisouna. Le sous-chapitre intitulé «Être Iroquois au temps de Jacques Cartier» a quelque chose de dramatique puisque Champlain ne trouvera qu'un «lieu vide» dans cette région laurentienne de l'Iroquoisie. D’autres régions de l'Iroquoisie allaient être au cœur de l'histoire de l'occupation européenne!

Mario Filion en prend large et juste avec les origines guerrières régionales et l'émergence d'une société rurale. Deux traits incontournables qui font partie de l'identité : le passage guerrier et pelletier et le jardin. JeanCharles Fortin poursuit avec «L'humanisation du territoire» (p. 169) qui aurait pu être la conclusion des chapitres sur la société rurale. Suit «Une économie agricole en transition» (p. 187) par Robert Lagassé.

Deux chapitres, le premier sur l'évolution des institutions, par Richard Lagrange, et le second, «La société, la politique et la culture» (p. 251), par Lagassé, précèdent les thèmes " Du champ à la banlieue " (beau titre) (p. 289) et «Le jardin du Québec» (le surnom régional bien connu) (p. 317). Je ne vois pas la logique rédactionnelle de ce noyau politique-culturel entre l'économie agricole et la banlieue.

Jean-Charles Fortin et Richard Lagrange présentent deux chapitres sur la sociabilité et les institutions régionales. Lorne Huston dresse un portrait sans retouche : «De la culture en région à la culture régionale (p. 427)» où il dresse de justes constats qui pourraient être généralisés : «[...] le local a tendance à devenir de plus en plus un lieu de consommation plutôt que de production culturelle."

Dans la conclusion générale, Jean-Charles Fortin, écrit : «Aujourd’hui la Montérégie centrale demeure pour de nombreux Québécois un des foyers les plus fidèles de leur personnalité [...]» (p. 506). Sans les nommer, on pourrait en dire autant de plusieurs autres régions et pays du Québec. 
Ce treizième volume des Régions du Québec est une solide contribution à la compréhension des singularités de la mosaïque nationale. La connaissance des Québec est peut-être la plus grande lacune de nos savoirs scolarisés. Non seulement, on n'apprend plus l'histoire du Québec, mais le moins que l'on puisse dire c'est que les régions ne sont que des toponymes souvent situés approximativement.

Pour terminer, j'aimerais signaler l'intérêt de l'iconographie et des graphiques, mais surtout la quantité et la très bonne qualité graphique et informative des cartes. Les cartes sont toujours indispensables dans une histoire globale. Elles sont, dans ce livre, un régal pour l'œil et le savoir. Elles sentent la bonne géo-histoire. Comme ce livre, qui est une synthèse réussie.

CHRISTIAN MORISSONNEAU

Département des sciences humaines Université du Québec à Trois-Rivières

HAVARD, Gilles, The Great Peace of Montre of of 1701. French-Native Diplomacy in the Seventeenth Century (Montreal, McGill-Queen's University Press, 200।), xvi-312 p.

La traduction anglaise de La grande paix de Montréal de 1701 : les voies de la diplomatie franco-amérindienne de Gilles Havard publié en 1992 par Recherches amérindiennes au Québec est bien plus qu'une simple traduction. L'auteur y a apporté des mises à jour importantes (surtout les travaux réalisés sur les Amérindiens des Grands Lacs) et sa bibliographie a, elle aussi, été refaite. Il répondait ainsi à la critique principale de son premier livre où il s'appuyait presque exclusivement sur la correspondance des autorités coloniales pour extrapoler sur la grande diplomatie de 1701 .

Havard a soigneusement examiné les échanges diplomatiques entre les nations autochtones et les Français qui ont culminé à la Grande Paix de 1701. En ce faisant, il s'éloigne de la tradition historiographique dont le précepte place l'avènement de Louis XIV ou les nombreux conflits armés entre la France et l'Angleterre en Amérique du Nord à partir des années 1680 comme ayant été les points marquants dans les annales de la colonie. L'auteur considère plutôt que les retombées économiques, politiques, et militaires de la Grande Paix de 1701 — qui annonçait la mission de neutralisation de l'expansion des colonies anglaises de la population française en Amérique du Nord - la place à un pied d'égalité avec les autres événements clefs dans l'histoire de la Nouvelle-France et demandait à être étudiée plus profondément (p. 179). 